\title{
A assistência aos expostos de Lisboa: A aprendizagem de ofícios da construção (1777-1812) ${ }^{1}$ \\ The assistance of foundlings in Lisbon: Learning the trade of construction (1777-1812)
}

Milene Alves ${ }^{2}$

Resumo: Numa tentativa de garantir a autonomia dos jovens que assistia, a Real Casa dos Expostos, sob a administração da Misericórdia de Lisboa, entre outras estratégias adotadas, promoveu a aprendizagem de diversas ocupações através da realização de contratos com mestres de vários ofícios, determinando as obrigações que estes deviam cumprir relativamente à instituição e aos aprendizes. O objetivo fundamental era prepará-los para o exercício da profissão como oficiais, de acordo com a hierarquia tripartida dos ofícios. Dos vários contratos de aprendizagem realizados entre 1777 e 1812, serão destacados os referentes à área da construção. Visa-se descortinar as características deste meio de inserção dos jovens assistidos por aquela instituição, num período da vida destes em que não era constrangida a manter o seu auxílio.

Palavras-Chaves: Real Casa dos Expostos; expostos; aprendizagem; construção.

\begin{abstract}
Among other strategies that the Real Casa dos Expostos, managed by Misericórdia of Lisbon, has adopted in an attempt to ensure the autonomy of the young people it has assisted, it has promoted training in various crafts through contracts with masters of differents trades, in which it has determined the obligations that they had to fulfil towards the institution and apprentices. The fundamental objective was to prepare them to work as journeymen, as stated by the tripartite hierarchy of crafts. Amongst contracts of apprenticeship signed between 1777 and 1812, I will highlight those relating to the building area. The aim is to characterize one of the strategies promoted by that institution to insert the young people it assisted, at a time in their lives when it was not constrained to maintain its assistance.
\end{abstract}

Keywords: Real Casa dos Expostos; foundlings; apprenticeship; building.

\footnotetext{
${ }^{1}$ Este artigo retoma dados de uma investigação mais abrangente anteriormente desenvolvida. Cf. Alves, 2013.

${ }^{2}$ CLEPUL, Faculdade de Letras, Universidade de Lisboa. ORCID ID: https://orcid.org/0000-0003-3995-7478.
} 


\section{Introdução}

Embora a aprendizagem de ofícios pelos jovens assistidos fosse uma prática comum na Europa, trata-se de uma temática pouco abordada nos estudos relativos a expostos. ${ }^{3}$ Para tal contribui a tipologia das fontes produzidas pelas instituições de acolhimento, o principal recurso para a caracterização da criação dos expostos. Registos de entrada de crianças, bilhetes que, por vezes, as acompanhavam e assentos relativos à entrega a amas são os documentos geralmente conservados nos fundos destas instituições. Como tal, os temas mais abordados são o motivo do abandono (legitimidade/ilegitimidade, condicionalismos económicos, etc.), o número considerável de crianças abandonadas, a sua elevada mortalidade e as características da criação. Apesar disso, entre as várias formas de inserção dos jovens assistidos finda a criação com as amas, a formação profissional é a mais estudada. ${ }^{4}$
Como resultado dos esforços desenvolvidos pela Misericórdia de Lisboa, através da Real Casa dos Expostos, para garantir a integração dos jovens que terminavam a criação com as amas, esta instituição conserva documentação que permite descortinar a sua atuação. Entre 1777 e 1915, foram realizados diversos contratos de aprendizagem com mestres de vários ofícios, inscritos em livros a tal destinados. ${ }^{5}$ Neste artigo, será analisado o primeiro dos seis livros pelos quais se distribui o registo destes contratos, abrangendo o período de dezembro de 1777 a janeiro de 1812 (AHSCML, Criação dos expostos, Expostos dados a ofício, liv. 1). Durante este período, a instituição assegurou formação profissional a 699 jovens expostos ou desamparados ${ }^{6}$. Destes, 25 foram encaminhados para a aprendizagem de uma ocupação na área da construção. Este estudo focar-se-á nos contratos realizados para estes 25 jovens, enquadrando-os no âmbito mais geral das aprendizagens contratadas no período em análise.

\footnotetext{
${ }^{3}$ Vejam-se, como obras de síntese sobre o tema dos expostos, Histoire, Économie et Société, 1987; Enfance abandonnée et société..., 1991; e Annales de Démographie Historique, 2007. Relativamente à Península Ibérica, destaquem-se Pérez Moreda, 1996 e Araújo e Ferreira, 2008. Para uma lista mais exaustiva de estudos sobre a criação de expostos, veja-se Lopes, 2010: 258-261 e 276-278.

${ }^{4}$ Quanto a estudos da realidade portuguesa que referem a formação profissional de expostos, mencionem-se Machado, 2010; Gouveia, 2001; e Silva, 2017, embora o tema central dos mesmos não seja a inserção profissional. No entanto, por tratar especificamente da matéria aqui em análise, destaque-se Abreu, 2005. Aí se analisam os contratos de trabalho realizados pela Misericórdia de Évora entre 1650 e 1837, os quais, no caso dos expostos do sexo masculino, determinavam igualmente a obrigação de ensino de um ofício.

${ }^{5}$ Antes de 1777 já a Misericórdia promovia a realização de contratos de aprendizagem com mestres de diferentes ofícios. No entanto, encontram-se mesclados com outros tipos de registos (Inventário da criação dos expostos..., 1998: 167, 289 e 335).

${ }^{6}$ Os expostos eram crianças abandonadas anonimamente, por norma nos primeiros dias de vida. Quanto aos desamparados, estavam inseridos em famílias que, por razões financeiras, morte de um ou vários elementos, cumprimento de penas, etc., ficavam sem apoio familiar. Estes representam apenas 1,3 \% dos 699 jovens para os quais foram efetuados contratos no período em análise. Na assistência a uns e a outros, eram tomadas as mesmas opções.
} 


\section{A criação de expostos}

pela Misericórdia de Lisboa:

\section{contextualização histórica}

Contrariamente ao que se verificava quanto ao auxílio a crianças ou jovens desamparados, a assistência aos expostos não estava prevista nos compromissos da Misericórdia de Lisboa, a primeira do reino, fundada em 1498. As ordenações também não referiram as misericórdias quando trataram das crianças abandonadas ou desamparadas. Desde as Ordenações Manuelinas, do início do século XVI, que estavam estabelecidas as entidades responsáveis pela criação dos expostos. No caso de uma criança não poder contar com o apoio familiar, a sua criação ficaria a cargo dos hospitais ou albergarias que existissem na cidade ou vila, quando os houvesse com bens destinados ao seu auxílio. Não existindo estas instituições, seriam os concelhos a responsabilizar-se por estas crianças, assegurando o sustento das mesmas através das suas rendas. Se tal não fosse possível, por estas serem insuficientes, os concelhos ficavam autorizados a lançar fintas para reunir a verba necessária (Ordenações manuelinas, 1984: 482). Estes princípios foram mantidos nas Ordenações Filipinas (Ordenações filipinas, 1985: 210-211). Não sendo obrigada pelas ordenações a garantir a criação dos expostos e não o prevendo nos seus compromissos, foi através da administração de um hospital - o Hospital Real de Todos-os-Santos - que a Misericórdia de Lisboa se envolveu na criação dos mesmos, situação semelhante à verificada em outras misericórdias do reino.

Seguindo o movimento de reestruturação das instituições de assistência que se verificava no Ocidente europeu desde meados do século XV, caracterizado pela concentração hospitalar, foi criado, em Lisboa, o Hospital Real de Todos-os-Santos, cuja construção se iniciou em 1492. Neste foram incorporados vários hospitais então existentes em Lisboa, passando o Hospital Real de Todos-os-Santos a administrar os bens dos mesmos e a assegurar o cumprimento das obrigações assistenciais e devocionais que antes pertenciam àquelas instituições (Abreu, 2002a: 417-418). Entre os hospitais integrados encontrava-se um que se dedicava ao auxílio a crianças desvalidas, o Hospital dos Meninos. Este, o primeiro fundado em Portugal para assistir estas crianças, foi criado, em 12737, por iniciativa da Rainha D. Beatriz, mulher de D. Afonso III (Alvim, 1984: 11). Seria financiado com recurso a esmolas e administrado pelo município (Ribeiro, 1998: 396). Desta forma, ao ser incorporado no Hospital Real de Todos-os-Santos, a sua obrigação de socorrer

\footnotetext{
${ }^{7}$ Esta é a data usualmente apontada para a fundação do hospital. No entanto, há investigadores que a colocam em causa. Sobre o assunto, veja-se Antão, 2020: 18-19, nota 57.
} 
as crianças desvalidas foi transferida para o novo hospital, ficando logo definida no seu regimento de 1504 (Regimento..., 1992: 128-130).

Após um período inicial de maior intervenção da Coroa, em que o provedor do hospital era nomeado pelo rei, em 1530 a administração da instituição foi entregue à Congregação de São João Evangelista, responsável também por outros hospitais. Durante 34 anos, foram os Loios que dirigiram o hospital. Em 1564, acedendo-se ao pedido do instituto religioso para que fosse desobrigado desta tarefa, a gestão do Hospital Real de Todosos-Santos foi confiada à Misericórdia de Lisboa, ficando responsável pelos serviços aí prestados, incluindo a criação dos expostos (Ramos, 2019: 51-59).Várias décadas mais tarde, em 1657, a Misericórdia determinou a criação da Mesa dos Enjeitados, a qual passou a superintender esta tarefa. Contudo, só em 1716 foi estabelecido o seu compromisso, determinando as obrigações dos vários intervenientes no processo. ${ }^{8}$

Assim se manteve a administração da criação dos expostos até 1768 , quando, por decreto de 4 de janeiro, foi determinada a união da Mesa dos Enjeitados à Mesa da Misericórdia. Ainda nesse ano, em fevereiro, foi doada a esta confraria a Igreja e Casa Professa de São Roque, pertença da Companhia de Jesus até 1759 , ano em que foi expulsa do reino. 0 espaço destinava-se à instalação da Misericórdia, do recolhimento das órfãs e dos expostos, os quais, após o terramoto de 1 de novembro de 1755 , com a consequente destruição do edifício do Hospital de Todos-os-Santos, onde eram acolhidos, tinham estado alojados em vários locais da cidade. Em 1771, mudaram-se finalmente para São Roque (Antão, 2020: 44-46 e 51).

O abandono anónimo de crianças em Lisboa só terminou no século seguinte, em 1870. Nesse ano, por ordem do provedor da Misericórdia de Lisboa, a roda, dispositivo cilíndrico que permitia manter o anonimato de quem abandonava, foi encerrada a 1 de dezembro.

Após o abandono na roda, as crianças eram recolhidas por uma das duas rodeiras a quem estava incumbida, alternadamente, esta tarefa. Para cada uma delas era elaborado um registo. Eram depois entregues a amas internas, que habitavam na Real Casa dos Expostos. Após o abandono, como em todas as fases em que estas crianças fossem acolhidas nas instalações da instituição, pretendia-se que a sua estada fosse o mais curta possível, tanto por questões financeiras como por motivos de saúde, uma vez que a sua acumulação facilitava a transmissão de doenças. Logo que possível, estas eram entregues a amas externas,

${ }^{8}$ Sobre a Mesa dos Enjeitados, veja-se Antão, 2020. 
de recrutamento voluntário, as quais as mantinham nas suas moradas. A sua criação era dividida em dois períodos, a criação de leite e a de seco (Costa, 1998: 31; Gouveia, 2001, I: 93). A criação de leite correspondia ao período em que era ainda necessário amamentar a criança, o qual, habitualmente, se prolongava por um ano e meio. A esta seguia-se a criação de seco, que, na Real Casa dos Expostos, durante o intervalo de tempo em análise, se prolongava até as crianças completarem 12 anos, embora se registem exceções. Era assim superior ao período definido em alvará de 31 de janeiro de 1775 . Pelo mesmo se determinava que o auxílio prestado às crianças abandonadas pela Misericórdia de Lisboa, através da Real Casa dos Expostos, devia findar quando aquelas completassem sete anos, ao contrário do que estava estabelecido até então, quando as mesmas deviam ser assistidas até aos nove anos. Terminada a criação a cargo da Misericórdia, a responsabilidade pelos expostos devia ser transferida para os juízes dos órfãos ${ }^{9}$ até que fossem emancipados ao completar 20 anos. Pretendia-se assim fazer face ao crescimento do número de crianças dependentes da instituição, sempre com problemas de financiamento, diminuindo o período em que eram assistidas (Silva, 1828: 4). Apesar do que havia ficado assente no referido alvará, a Misericórdia de Lisboa assegurava o pagamento da criação dos expostos ou o seu acolhimento além da idade ali estabelecida, como, aliás, já praticava anteriormente, facto censurado naquele documento pelos inconvenientes que originava a certeza da proteção da Misericórdia, dificultando a integração dos jovens numa nova família ou o exercício de uma ocupação, pela possibilidade de serem novamente auxiliados por aquela instituição. A Misericórdia não só prolongava a criação dos expostos como muitas vezes se substituía aos juízes dos órfãos na definição do seu destino após o término da criação remunerada com as amas.

Para os expostos que terminavam a criação de seco, o mais usual era que permanecessem com as amas que os haviam criado. Esta era a solução privilegiada pelos responsáveis pela Real Casa dos Expostos caso aqueles tivessem sido bem tratados. Tomando como exemplo as crianças abandonadas entre 1786 e 1790 e que terminaram o período da criação, 53 \% mantiveram-se com as amas (Gouveia, 2001: 67). Para as restantes, um dos destinos que se lhes proporcionava, essencialmente para as do sexo masculino, era a aprendizagem de um ofício, sempre realizada no exterior da instituição. ${ }^{10}$

\footnotetext{
${ }^{9}$ Os juízes dos órfãos tinham como principal incumbência assegurar a correta administração dos bens dos órfãos e a sua criação e educação.

${ }^{10}$ Outras instituições europeias tinham oficinas a funcionar nas suas instalações, onde a aprendizagem de um ofício podia decorrer. Veja-se, como exemplo, o caso do hospício de Leão, em Espanha (Martín García, 2008).
} 
Tentava-se assim assegurar a possibilidade de futuramente poderem garantir o seu sustento.

\section{A inserção profissional dos jovens:} a atuação da Real Casa dos Expostos

Para garantir a formação profissional dos expostos, a opção usual era a realização de contratos de aprendizagem com mestres de vários mesteres. Segundo os regimentos dos diversos ofícios, era aos mestres que estava reservada a formação de aprendizes, assim como a manutenção de oficinas/lojas. 0 trabalho oficinal, juntamente com o caseiro, continuava a ser a principal forma de produção em Portugal no século XVIII, não obstante os estímulos à criação de manufaturas. Assim, cada mestre, responsável por uma loja apenas, era auxiliado na produção por oficiais (estádio intermédio entre o iniciante no ofício, o aprendiz, e aquele que era já especialista, o mestre) e por um ou dois aprendizes (no caso de o mestre pretender acolher um segundo aprendiz, só o poderia fazer na fase final do período de aprendizagem do primeiro) (Langhans, 1943, I).

Apesar de os contratos realizados com mestres serem a solução mais utilizada para assegurar a formação num ofício, a Misericórdia de Lisboa colaborou também com grandes estabelecimentos fabris para o mesmo fim. Os arsenais reais da Marinha e do Exército e a Real Fábrica de Cordoaria receberam igualmente jovens encaminhados por aquela instituição. Refira-se ainda que também a Real Casa Pia de Lisboa os recebeu nas suas oficinas (Alves, 2013: 86 e 88-93).

Pouco se conhece sobre os princípios que orientavam os responsáveis pela Real Casa dos Expostos quanto ao encaminhamento de jovens para a aprendizagem de um ofício. Para o período em estudo, o primeiro documento encontrado que fornece alguns dados sobre as particularidades do processo é um aviso do príncipe regente, D.João, dirigido ao Senado da Câmara de Lisboa a 11 de setembro de 1804. Segundo este aviso, seria disponibilizada ao presidente do Senado, a cada ano, uma lista dos jovens assistidos pela Misericórdia de Lisboa que estivessem em idade de iniciar a formação profissional, sem definir a idade. O presidente daquele órgão distribui-los-ia então pelos juízes dos ofícios ${ }^{11}$ que fossem controlados pelo Senado, os quais, por sua vez, os dividiriam pelos mestres. Os juízes deviam ainda informar-se sobre o comportamento dos mestres em relação aos aprendizes $(A M L-A H$, liv. 4 de registo da Casa dos Vinte e Quatro, fls. 50v.-51v. [corrigidos para 53v.-54v.]).

De acordo com o mesmo documento, estas aprendizagens deviam reger-se pelas normas estabelecidas nos regimentos. Estes, definidos pelos membros do respetivo ofício,

\footnotetext{
${ }^{11} \mathrm{Em}$ número de dois em cada ofício, sendo obrigatoriamente mestres, eram eleitos anualmente. Tinham como função essencial garantir o cumprimento das normas definidas nos regimentos, incluindo das relacionadas com a aprendizagem.
} 
eram confirmados pelo Senado da Câmara. Entre as várias matérias regulamentadas contava-se a aprendizagem. Determinava-se, por exemplo, a obrigação da matrícula dos aprendizes, realizada pelo escrivão do ofício, o que permitia o controlo do período de formação. Quanto à duração desta, podia ser estabelecido um período exato ou um tempo mínimo (Langhans, 1943).

Não obstante ser difícil avaliar a real abrangência da aplicação das normas assentes neste aviso, já que poucos contratos referem o facto de terem sido realizados no seguimento do que ali foi estabelecido, registe-se que, logo a 13 de dezembro do mesmo ano, o presidente do Senado referia que tinha já recebido uma lista dos expostos que deviam ser distribuídos por diferentes ofícios tendo em conta a sua idade e a vocação demonstrada (AML - AH, liv. 4 de registo da Casa dos Vinte e Quatro, fls. 65v. [corrigido para 68v.]). Contudo, o aviso do príncipe regente possivelmente formalizaria apenas o que era já praticado, pois existem matrículas de expostos como aprendizes de ofícios sob o controlo do Senado anteriores à emissão do mesmo.

Apesar da referência, que surge em vários contextos, ao facto de a escolha dos ofícios que os expostos deveriam aprender depender da vocação dos mesmos, seria sobretudo a dis- ponibilidade de mestres para os receber que a imporia. Relembre-se que as instituições que assistiam os expostos tinham como objetivo serem apenas locais de trânsito, onde as crianças e os jovens não deveriam permanecer por longos períodos. Assim, logo que a oportunidade se apresentasse, os jovens seriam encaminhados para a aprendizagem, embora se admita que, quando possível, os seus interesses fossem tidos em conta.

Assim, quando um mestre demonstrava interesse em receber como aprendiz um dos jovens assistidos pela Real Casa dos Expostos era realizado um contrato entre esta instituição e aquele para formalizar a relação estabelecida. Estes acordos eram registados pelo secretário da instituição, estando presente o mestre ou, em casos raros, um procurador do mesmo.Cada contrato, além de identificar o mestre, sendo anotado o seu nome, a sua morada e a sua ocupação, identificava igualmente o exposto pelo qual o mestre ficaria responsável ${ }^{12}$. 0 mestre ficava obrigado a ensinar o seu ofício durante um período que ficava também definido no contrato. 0 objetivo principal era então que, no final desse período, o jovem estivesse capaz de trabalhar como oficial na ocupação em causa. Não sendo cumprida esta obrigação, o mestre ficava obrigado a pagar-lhe soldadas como oficial até que fosse capaz de trabalhar como tal.

${ }^{12}$ A maioria destes contratos respeitava a apenas um jovem, embora se verifiquem exceções. 
Além deste dever, o mestre era também responsável pelo sustento do jovem durante 0 período em que decorresse a aprendizagem, não recebendo compensação financeira por parte da Real Casa dos Expostos. A contrapartida pelos gastos que faria com a manutenção do jovem adviria do trabalho por este realizado. Mesmo no período inicial da formação, os aprendizes realizariam tarefas que não estavam dependentes de conhecimentos específicos e que poderiam não estar diretamente relacionadas com a prática do ofício, como limpezas ou entregas. A aprendizagem decorreria em simultâneo com este tipo de serviços, necessário para assegurar o funcionamento da loja.

Uma vez que estes contratos implicavam a definição de um conjunto de obrigações a cumprir pelo mestre, a grande maioria implicava a apresentação de um fiador, que ficaria responsável pela sua observância na impossibili- dade de o mestre o fazer. Quanto à Real Casa dos Expostos, devia assegurar que os jovens fossem bem tratados pelos mestres e que a aprendizagem fosse concluída.

Em geral, os assentos relativos aos encaminhamentos para os arsenais do Exército e da Marinha e para a Cordoaria não tinham as mesmas características. Nestes casos, era apenas feito um registo conjunto com uma anotação identificando cada um dos jovens, o estabelecimento fabril que os receberia, a data em que eram encaminhados e, por vezes, o ofício a que se destinavam.

\section{A aprendizagem de ofícios da construção}

Entre os diversos ofícios para os quais foram orientados expostos, e desamparados, assistidos pela Real Casa dos Expostos contam-se os da área da construção.

\begin{tabular}{c|c|c|c|c|c|c} 
Ofício & Variantes & Aprendizes & $\begin{array}{c}\text { Idade } \\
\text { (min-máx.) }\end{array}$ & Idade média & $\begin{array}{c}\text { Tempo } \\
\text { de aprendizagem } \\
\text { (mín-máx.) }\end{array}$ & $\begin{array}{c}\text { Tempo médio } \\
\text { de aprendizagem }\end{array}$ \\
\hline $\begin{array}{c}\text { Cabouqueiro } \\
\text { Cabouqueiro } \\
\text { de pedra } \\
\text { branca }\end{array}$ & 2 & - & 12 & - & 5 \\
\hline $\begin{array}{c}\text { Carpinteiro de } \\
\text { casas }\end{array}$ & - & 5 & - & 13 & $5-6$ & 5,4 \\
\hline Pedreiro & $\begin{array}{c}\text { Canteiro; } \\
\text { pedreiro } \\
\text { e canteiro13 }\end{array}$ & 11 & $12-17$ & 12,8 & $4-7$ & 5,5 \\
\hline
\end{tabular}

13 O ofício de canteiro é apresentado como uma variante do de pedreiro por a associação surgir num dos contratos elaborados, em que a obrigação era o ensino do ofício de pedreiro e canteiro. De forma a possibilitar a apresentação dos dados de forma mais clara, manteve-se a associação. 


\begin{tabular}{c|c|c|c|c|c|c}
\hline Oficio & Variantes & Aprendizes & $\begin{array}{c}\text { Idade } \\
\text { (mín-máx.) }\end{array}$ & Idade média & $\begin{array}{c}\text { Tempo } \\
\text { de aprendizagem } \\
\text { (mín-máx.) }\end{array}$ & $\begin{array}{c}\text { Tempo médio } \\
\text { de aprendizagem }\end{array}$ \\
\hline Pintor & - & 5 & $11-13$ & 12 & $6-8$ & 6,6 \\
\hline Vidraceiro & - & 2 & - & - & $3,5-5$ & 4,3
\end{tabular}

Fig. 1: Elenco dos ofícios da construção incluídos nos contratos de aprendizagem. ${ }^{14}$

Os contratos de aprendizagem referentes a estes ofícios distribuem-se ao longo do período estudado, tendo o primeiro sido registado em 1778 e o último em 1811.

Como seria expectável, devido às particularidades das funções exercidas nestes ofícios, todos os aprendizes são do sexo masculino. É, aliás, uma característica dos contratos em estudo. Outras ocupações eram normalmente destinadas às jovens do sexo feminino após terminarem a criação de seco. A aprendizagem formal de um ofício destinava-se essencialmente a iniciar os rapazes no exercício de uma ocupação. Era assim que era definida nos regimentos, e a prática confirma-o. Nos contratos analisados, as poucas jovens para as quais foi realizado um contrato ficaram limitadas ao sector têxtil, sendo encaminhadas para os ofícios de tecedeira, linheira e alfaiate.

Das ocupações incluídas na área da construção, destacam-se claramente as que estão relacionadas com o trabalho da pedra: cabouqueiro e pedreiro. Para a sua aprendizagem foram realizados contratos envolvendo 13 jovens, o que corresponde a $52 \%$ dos assentos. Mesmo considerando os ofícios individualmente, o trabalho da pedra continua em destaque, uma vez que o ofício para o qual mais aprendizes foram encaminhados foi o de pedreiro, tendo sido realizados 11 contratos prevendo a aprendizagem do mesmo. Pelo contrário, os de cabouqueiro e de vidraceiro foram aqueles para os quais se estabeleceram menos aprendizagens, tendo sido

\footnotetext{
${ }^{14}$ Os dados apresentados foram recolhidos em AHSCML, Criação dos expostos, Entrada, liv. 36, fl. 366v., n. ${ }^{\circ}$ 451; AHSCML, Criação dos expostos, Entrada e batismo, liv. 3, fl. 382, n. ${ }^{\circ}$ 287; liv. 4, fl. 22, n. ${ }^{\circ}$ 369; liv. 7, fl. 115v., n. ${ }^{0}$ 1135; liv. 15, fl. 287v., n. ${ }^{\circ}$ 236; liv. 17, fl. 347v., n. ${ }^{\circ}$ 476; liv. 19, fl. 310, n. ${ }^{\circ}$ 595; liv. 20, fl. 240v., n. ${ }^{\circ}$ 1239; liv. 22, fl. 320v., n. ${ }^{\circ}$ 76; liv. 23, fl. 82v., n. ${ }^{\circ}$ 384; liv. 27, fl. 17, n. ${ }^{\circ} 247$; liv. 34, fl. 44v., n. 1051 e AHSCML, Criação dos expostos, Expostos dados a ofício, liv. 1, fls. 20, 60v., 69, 71v., 81, 88v., 192v., 195, 210v., 221, 223v., 233v., 292, 303v., 327v., 332v., 340, 365v., 377, 391, 393, 341v., 351, 358 e 366v. O agrupamento dos ofícios tem por base a sugestão de Jorge Borges de Macedo na sua obra Problemas de história da indústria portuguesa no século XVIII (1982), em que adotou como critério para o seu estabelecimento o material trabalhado ou a técnica utilizada. No caso do ofício de carpinteiro de casas, optou-se por inseri-lo aqui na área da construção e não na do trabalho da madeira, por ser o seu campo de intervenção.
} 
realizados dois contratos para cada um dos referidos ofícios.

Relativamente à idade média no início da aprendizagem, uma vez que a criação remunerada costumava prolongar-se até os jovens completarem 12 anos, seria expectável que a mesma se situasse próxima deste valor. Dos 25 jovens para os quais foram realizados estes contratos, apenas para 12 foi possível apurar a idade. De facto, a média de idades destes jovens no momento em que iniciavam aprendizagem era de 12,6 anos. Contudo, verifica-se uma amplitude de idades considerável, uma vez que o aprendiz mais novo tinha 11 anos quando começou a formação no ofício de pintor e o mais velho, encaminhado para a aprendizagem do ofício de pedreiro, tinha já 17 anos.

As idades apresentadas respeitam sempre ao início da aprendizagem e não à data da realização do contrato. Isto porque, se na maioria dos casos o registo do contrato marcava o começo da formação profissional, três assentos foram efetuados em data posterior ao início da mesma, um dos quais cerca de um ano depois. Assim, no caso dos três jovens abrangidos, a iniciativa de os destinar à aprendizagem de um ofício não teria partido da Real Casa dos Expostos. A instituição ter-se-ia limitado a sancionar a mesma, formalizando-a através de um contrato (AHSCML, Criação dos expostos, Expostos dados a ofício, liv. 1, fls. 69, 233v. e 366v.).

Quanto ao intervalo de tempo definido para a formação, esta prolongava-se, em média, por 5,6 anos. ${ }^{15}$ É no ofício de pintor que se registam as aprendizagens mais longas, as quais se estendiam, em média, por 6,6 anos. Mesmo analisando os períodos máximo e o mínimo de aprendizagem registados em cada ofício, é o de pintor que se destaca novamente como aquele que apresenta um maior número de anos de formação. Pelo contrário, o de vidraceiro é o que tem o tempo médio de aprendizagem mais baixo, 4,3 anos. Foi também para este ofício que se realizou o assento que previa o menor período de aprendizagem: 3,5 anos. Nos restantes, cabouqueiro, carpinteiro de casas e pedreiro, a aprendizagem devia prolongar-se entre 5 e 5,5 anos.

As moradas dos mestres incluídos nestes contratos podem fornecer indícios quanto aos locais onde decorriam as aprendizagens, embora o trabalho da construção não se coadunasse com o exercício de tarefas numa oficina. Revelam sobretudo a área geográfica de influência da Misericórdia de Lisboa no que diz respeito à criação dos expostos.

\footnotetext{
${ }^{15}$ Apenas no caso de um aprendiz não foi possível definir o tempo de duração da aprendizagem, já que se estabelecia somente que a mesma devia prolongar-se até o jovem completar 20 anos (AHSCML, Criação dos expostos, Expostos dados a ofício, liv. 1, fl. 69). Sendo a sua idade desconhecida, não foi possível determinar quanto tempo devia durar a formação.
} 
Dos 20 mestres para os quais foi mencionado o local de morada, 8 habitavam na cidade de Lisboa ou no seu termo, ou seja, 40 \%. Os restantes distribuíam-se por localidades relativamente próximas desta cidade, como, por exemplo, Leiria, Lourinhã, Santarém, Sesimbra e Vila Franca de Xira. Se forem tidos em conta todos os contratos de aprendizagem realizados no período em estudo, verifica-se uma diferença significativa quanto ao local de morada dos mestres. Se nos ofícios ligados à construção só $40 \%$ destes habitavam em Lisboa (cidade ou termo), quando considerado o total de assentos, $81,5 \%$ dos mestres ou fábricas para os quais foi possível determinar a localização estavam estabelecidos em Lisboa (Alves, 2013: 98).

O início da aprendizagem de um ofício implicava, de uma forma geral, a alteração do local de habitação do aprendiz, indo este morar com a família do mestre. Por isso, nestes contratos, por norma, os responsáveis anteriores por estes jovens estão ausentes. Contudo, existem algumas exceções, em que a concretização desses assentos não implicou um corte com aqueles que os haviam criado. Assim, registam-se situações em que o mestre que garantia a formação tinha sido responsável por um período da criação de seco ou em que era o marido da última ama do jovem. Nestes casos, quem se obrigava a assegurar que o jovem em causa aprendesse um ofício era também o agente da formação. Contudo, era também possível que o contrato de aprendi- zagem fosse realizado com alguém que teria a tarefa de mandar ensinar um determinado ofício. Foi o que se verificou em alguns assentos, em que as amas dos expostos visados ficaram obrigadas a garantir que os jovens aprendessem os ofícios determinados no contrato, sabendo-se que num dos casos seria o marido da ama, pedreiro, a ensinar o ofício ao exposto (AHSCML, Criação dos expostos, Expostos dados a ofício, liv. 1, fl. 340).

Após o registo dos contratos de aprendizagem, as informações relativas aos jovens abrangidos são escassas, sendo difícil avaliar o sucesso da empresa da Real Casa dos Expostos. Dos 25 jovens para os quais foram realizados contratos para a aprendizagem de ofícios da área da construção apenas de 6 se conhece o destino após o respetivo assento (AHSCML, Criação dos expostos, Expostos dados a ofício, liv. 1, fls. 20, 60v., 81, 88v., 341v. e 366v.). Mesmo nestes casos, apenas é possível descortinar o seu destino no momento em que as notas ao contrato foram acrescentadas. Nesse grupo de seis jovens, foi registada apenas uma fuga, ignorando-se o que a causou e quando se realizou (AHSCML, Criação dos expostos, Expostos dados a ofício, liv. 1, fl. 366v.). Outra causa para a interrupção da aprendizagem era a devolução dos jovens à Real Casa dos Expostos, onde voltavam a ser acolhidos. Foram averbadas quatro devoluções de aprendizes (AHSCML, Criação dos expostos, Expostos dados a ofício, liv. 1, fls. 20, 81, 88v. e 341v.). Tal como no caso da fuga, também 
a motivação para as devoluções à instituição é desconhecida. Estas tanto se podiam concretizar apenas algumas semanas depois da realização do contrato como após vários anos. Foi o que se verificou com um aprendiz do ofício de pintor, devolvido após cumprir quatro dos sete anos definidos para a aprendizagem (AHSCML, Criação dos expostos, Expostos dados a ofício, liv. 1, fl. 20). Mencione-se, aliás, que dos quatro jovens entregues, três aprendiam o ofício de pintor. No entanto, desconhecendo-se as motivações das devoluções, dificilmente se pode estabelecer uma relação entre estes factos.

As fugas e as devoluções podiam conduzir à realização de novos contratos de aprendizagem, nem sempre referentes ao ofício inicialmente previsto. Foi o que se verificou no caso de dois aprendizes de pintor devolvidos à Real Casa dos Expostos. Para um deles, acima referido, que tinha aprendido o ofício de pintor durante quatro anos, foi realizado um novo assento, no mesmo dia em que foi devolvido, para que fosse formado no ofício de alfaiate durante seis anos (AHSCML, Criação dos expostos, Expostos dados a ofício, liv. 1, fls. 20 [pintor] e 66v. [alfaiate]). Passou assim da área da construção para a têxtil. Tal justificar-se-ia pelo facto de a escolha do ofício a aprender dever ser condicionada, sobretudo, pela procura de aprendizes pelos mestres, como indicado anteriormente, o que se sobreporia a outras situações, como a garantia da continuidade da formação num determinado ofício. O mesmo se teria verificado com o outro aprendiz de pintor, já devolvido anteriormente, por ter sido considerado incapaz de aprender o ofício de alfaiate. Restituído, mais uma vez, à Real Casa dos Expostos, foi visado num novo contrato, realizado para a aprendizagem do ofício de sapateiro, cerca de um ano e meio depois de ter sido devolvido. Durante este período, foi entregue a um familiar do juiz de fora de Alenquer, com obrigação de o sustentar (AHSCML, Criação dos expostos, Expostos dados a ofício, liv. 1, fls. 85 [alfaiate], $88 \mathrm{v}$. [pintor] e 113 [sapateiro]).

Sendo o objetivo fundamental destes contratos a preparação dos jovens para trabalharem na profissão como oficiais, apenas quanto a um deles foi registado o término da formação, embora de um ofício diferente do inicialmente previsto. À Real Casa dos Expostos foi comunicado que um dos aprendizes de pedreiro trabalhava como oficial, mas do ofício de alfaiate (AHSCML, Criação dos expostos, Expostos dados a ofício, liv. 1, fl. 60v.). Só então a instituição teria tido conhecimento desta alteração, já que a aprendizagem do ofício de alfaiate não foi formalizada pela mesma. Relativamente aos restantes jovens, nada se sabe quanto ao possível exercício de um ofício.

\section{Conclusão}

Apesar dos esforços desenvolvidos pela Real Casa dos Expostos de Lisboa, pouco se sabe sobre os resultados efetivos da sua atuação na tentativa de assegurar a aprendizagem de ofí- 
cios aos jovens que assistia, assegurando-lhes a aquisição de conhecimentos que thes permitiriam, no futuro, garantir a sobrevivência sem a intervenção da instituição. A informação quanto à concretização do objetivo essencial que motivava a realização destes assentos, 0 exercício da ocupação como oficial, está quase sempre ausente. Os contratos analisados registam, muitas vezes, apenas as circunstâncias imediatas da sua realização, representando para alguns jovens a última informação quanto ao seu destino. São, contudo, reveladores das estratégias desenvolvidas no auxílio a estes jovens e do futuro que se perspetivava para os mesmos.

\section{Bibliografia}

\section{Manuscrita}

Arquivo Histórico da Santa Casa da Misericórdia de Lisboa (AHSCML), Criação dos expostos, Entrada (CE/EE/EB/01), liv. 36, 1763-1766;

Arquivo Histórico da Santa Casa da Misericórdia de Lisboa (AHSCML), Criação dos expostos, Entrada e batismo (CE/EE/EB/02), livs. 3 (1777-1778), 4 (1778-1779), 7 (1780-1781), 15 (1789-1790), 17 (1790-1791), 19 (1791-1792), 20 (1792-1793), 22 (1793-1794), 23 (1794), 27 (1796), 34 (1799-1800);

Arquivo Histórico da Santa Casa da Misericórdia de Lisboa (AHSCML), Criação dos expostos, Expostos dados a ofício (CE/EA/EO/01), liv. 1, 1777-1812;

Arquivo Municipal de Lisboa - Arquivo Histórico (AML - AH), liv. 4 de registo da Casa dos Vinte e Quatro, 1776-1806;

\section{Impressa}

Abreu, L. (2002a). A especificidade do sistema de assistência pública português: Linhas estruturantes. Arquipélago. História, 6: 417-434;
Abreu, L. (2002b). As misericórdias de D. Filipe I a D. João V. Em: J.P. Paiva (coord.). Portugaliae monumenta misericordiarum. União das Misericórdias Portuguesas. Lisboa. 1. ${ }^{\circ}$ vol.;

Abreu, L. (2005). Un destin exceptionnel: Les enfants abandonnés au travail (Évora, 1650-1837). Annales de Démographie Historique, 110: 165-183;

Alves, M.L.G. (2013). A Real Casa dos Expostos de Lisboa e a aprendizagem de ofícios (1777-1812). Tese de Mestrado em História Moderna e Contemporânea. Faculdade de Letras, Universidade de Lisboa. Lisboa. 138 pp.;

Alvim, M.H.V.B. (1984). Em torno dos expostos. As duas primeiras casas de expostos portuguesas. Revista de História, 1: 147-166;

Annales de Démographie Historique (2007), 114; Araújo, M.M.L. e Ferreira, F.M. (orgs.) (2008). A infância no universo assistencial da Península Ibérica (sécs. XVI-XIX). Instituto de Ciências Sociais da Universidade do Minho. Braga;

Bardet, J.-P., Luc, J.-N., Robin-Romero, I. e Rollet, C. (dirs.) (2003). Lorsque l'enfant grandit. Entre dépendance et autonomie. Presses de l'Université de Paris-Sorbonne. Paris;

Costa, M.T.F. (1998). O abandono e a roda. A Real Casa dos Expostos de Lisboa, 1780-1784. Monografia final do curso de Pós-Graduação em História Regional e Local. Faculdade de Letras, Universidade de Lisboa. Lisboa.114 pp.;

Enfance abandonnée et société en Europe, $\mathrm{XIV}^{\mathrm{e}} \mathrm{XX}$ siècle. Actes du Colloque International de Rome (30 et 31 janvier 1987) (1991). École Française de Rome. Rome;

Gouveia, M.L.F. (2001). O Hospital Real dos Expostos de Lisboa (1786-1790). Aspectos sociais e demográficos. Tese de Mestrado em História Regional e Local. Faculdade de Letras, Universidade de Lisboa. Lisboa. 2 vols.;

Histoire, Économie et Société (1987), 6 (3);

Inventário da criação dos expostos do Arquivo Histórico da Santa Casa da Misericórdia de Lisboa (1998). Santa Casa da Misericórdia de Lisboa. Lisboa; 
Lagoá, M.J. e Silva, F.R. (1998). A formação profissional no Antigo Regime. Em: J.F. Alves (coord.). A indústria portuense em perspectiva histórica. Actas do colóquio. Centro Leonardo Coimbra da Faculdade de Letras da Universidade do Porto. Porto;

Langhans, F.P. (compil.) (1943-1946). As corporações dos ofícios mecânicos. Subsídios para a sua história. (Pref. de Marcello Caetano). Imprensa Nacional de Lisboa. Lisboa. 2 vols.;

Lopes, M.A. (2010). Protecção social em Portugal na Idade Moderna. Guia de estudo e investigação. Imprensa da Universidade de Coimbra. Coimbra;

Macedo, J.B. (1982). Problemas de história da indústria portuguesa no século XVIII. (2. ${ }^{\mathrm{a}}$ ed.). Editorial Querco. Lisboa;

Machado, M.F. (2010). Os órfãos e os enjeitados da cidade e do termo do Porto (1500-1580). Tese de Doutoramento em História. Faculdade de Letras, Universidade do Porto. Porto. 398 pp.;

Martín García, A. (2008). La educación de la infancia desvalida en la España de finales del Antiguo Régimen: El hospicio de la cidade de León. Em: M.M.L. Araújo e F.M. Ferreira (orgs.). A infância no universo assistencial da Península Ibérica (sécs. XVI-XIX). Instituto de Ciências Sociais da Universidade do Minho. Braga;

Ordenações filipinas (1985). Fundação Calouste Gulbenkian. Lisboa. 1. ${ }^{\circ}$ vol.;

Ordenações manuelinas (1984). Fundação Calouste Gulbenkian. Lisboa. 1. ${ }^{\circ}$ vol.;

Pérez Moreda, V. (coord.) (1996). Expostos e ilegítimos na realidade ibérica do século XVI ao presente. Actas do III Congresso da Associação Ibérica de Demografia Histórica. Edições Afrontamento. Porto;

Ramos, R.I.G. (2019). O Hospital de Todos os Santos. História, memória e património arquivístico (sécs. XVI-XVIII). Tese de Doutoramento em História: Mudança e Continuidade num Mundo Global. Instituto de Investigação e Formação Avançada, Universidade de Évora. Évora. 335 pp.
Regimento do Hospital de Todos-os-Santos (1992). (Pref., transcrição, glossário, notas e índice remissivo de Abílio José Salgado e Anastásia Mestrinho Salgado). Comissão Organizadora do V Centenário da Fundação do Hospital Real de Todos-os-Santos. S. L.;

Ribeiro, V. (1998). A Santa Casa da Misericórdia de Lisboa. Subsídios para a sua história. Academia das Ciências de Lisboa. Lisboa;

Sá, I.G. (1995). A circulação de crianças na Europa do sul. $O$ caso dos expostos do Porto no século XVIII. Fundação Calouste Gulbenkian, Junta Nacional de Investigação Científica e Tecnológica. Lisboa;

Serrão, J.V. (1998). A Misericórdia de Lisboa. Quinhentos anos de história. Livros Horizonte. Lisboa;

Silva, A.D. (compil.) (1828). Collecção da Legislacção Portugueza desde a Última Compilação das Ordenações. Legislação de 1775 a 1790. Tipografia Maigrense. Lisboa;

Silva, A.I.C. (2017). A norma e o desvio. História da evolução dos compromissos das misericórdias portuguesas. Em: J.P. Paiva (coord.). Portugaliae monumenta misericordiarum. União das Misericórdias Portuguesas. Lisboa. 10. ${ }^{\circ}$ vol.;

Silva, A.I.C.P. (2017). Assistência social em Portugal na Monarquia Constitucional (1834-1910): Da doutrina política à prática no Alto Alentejo. Tese de Doutoramento em Altos Estudos em História - Ramo: Época Contemporânea. Faculdade de Letras, Universidade de Coimbra. Coimbra. 999 pp.;

\section{Digital}

Antão, N.M. (2020). A Mesa dos Enjeitados e a função assistencial da criação dos expostos na Lisboa moderna (1657-1768): Estudo orgânico-funcional.Santa Casa da Misericórdia de Lisboa. Lisboa. Acedido a 16 de maio de 2021, em: https://backoffice.scml.pt/wp-content/uplo ads/2020/04/A-Mesa-dos-Enjeitados.pdf. 